\title{
Surface Topology Evaluation of P20 Steel by Multipass Cutting Strategy in Wire EDM
}

\author{
Mahendra B Thakor ${ }^{1}$, Ms. Nehal Joshi ${ }^{2}$ \\ ${ }^{1} 4^{\text {th }}$ semester (M.E Production), Department of Mechanical Engineering,SVBIT, Gandhinagar-382650 \\ ${ }^{2}$ Assistant Professor, Department of Mechanical Engineering,SVBIT, Gandhinagar-382650
}

\begin{abstract}
Wire EDM process eliminates the work materials by a series of electrical sparks between the workpiece and wire electrode. These sparks creates craters and burs on the machined surface. Machined surface with poor integrity is a major disadvantage of WEDM. This work presents the investigation on multi-pass cutting operation (single rough cut followed by multi trim cuts) in wire electrical discharge machining (WEDM) of p20 steel. Trim cuts were performed using Taguchi's design of experiment method to investigate the influence of discharge current (Ip), pulse-on time (Ton), pulse-off time, servo voltage and number of trim cuts on two performance characteristics namely cutting rate and surface roughness (SR).Experiments were performed using $0.25 \mathrm{~mm}$ brass wire. Result shows that the surface finish improves significantly in trim cutting operation.
\end{abstract}

Keywords: WEDM, Trim cutting, P20 steel, Brass wire, Zinc coated Wire

\section{INTRODUCTION}

Wire electrical discharge machining is an electro thermal process, which removes electrical conductive materials by mean of repetitive electric sparks discharge from a pulsating DC power supply across a spark gap between a continuous moving conductive wire and work piece (Figure 1). Each discharge melts or vaporizes a small amount of materials from the machined surface which is flushed away by the dielectric fluid flowing between wire electrode and machined surfaced. WEDM provides the best alternatives for machining the exotic, conductive and hard materials with the scope of generating intricate shape and profile.

The defects are due to high heat energy generated across the electrodes and re-solidification of melted debris's that do not flushed quickly out of a narrow spark gap. Result shows that using single trim cutting operation with correct machining parameters and appropriate wire offset, surface characteristics can be improved irrespective of the rough cutting operation.

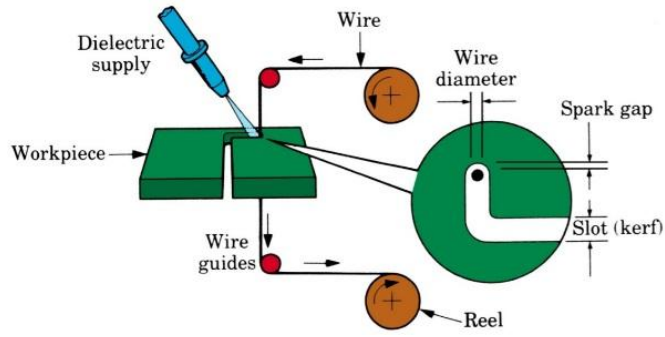

Fig 1: Basic WEDM Principle

Despite many research works on WEDM, not much literature is available on uncleared materials after rough cutting operation in die cavity. It is very important to minimize this uncleared materials in order to achieve good die performance and quality of the final components. Therefore, the aim of this paper is to present some investigations on surface projections appeared after rough cutting operation in intricate machining on WEDM.

\subsection{Multipass cutting strategy}

The multi pass cutting operation in WEDM includes a rough cut or main cut with high discharge energy followed by trim cuts at low discharge energy. Fig 2shows the schematic representation of multi pass

Cutting operation. Rough cut or first cut removes the maximum possible material from the work surface while in trim cutting or finish cutting operation, wire electrode traces back the same path with certain value of wire offset from work surface machined in rough cut, with an aim to remove a thin layer of work surface as shown in Fig 2.

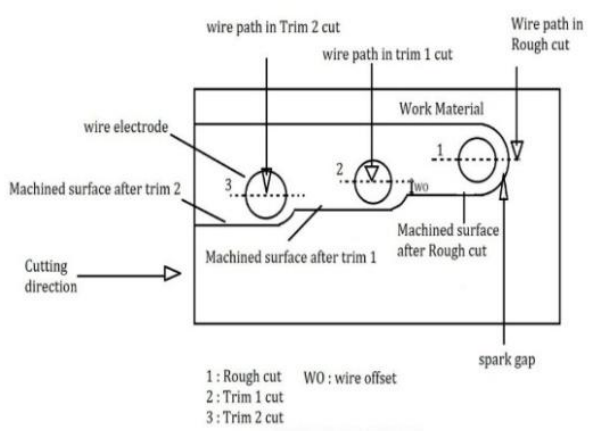

Fig 2: basics of multipass cutting strategy 
Rough cut is generally performed at high discharge energy that leads to several defects like recast layer, high heat affected zone and micro cracks and greater thickness of recast layer. Using trim cutting operation after a rough cut recast layer and unwanted surface flaws can be removed by selecting proper parameters.

\section{MATERIALS ANDMETHODOLOGY}

\section{$2.1 P 20$ :}

P20 Steel Material is a versatile, low alloy tool steel that is characterized by good toughness at moderate strength levels. The special purpose P20 mold steel plate is commonly used for plastic injection mold cavities and tooling and for die casting dies.

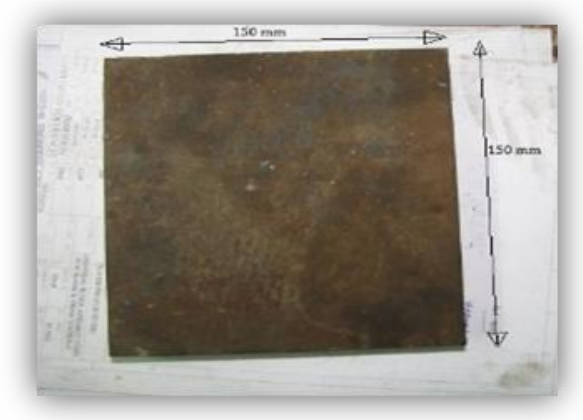

Fig 3 : $150 \times 150 \times 25$ mm P20 steel

\subsection{Chemical composition of P20steel}

Table 2.1: Composition of P20 steel

\begin{tabular}{|l|l|l|l|l|l|l|l|l|}
\hline Element & C & Si & Vil & P & S & C & C & M \\
\hline $\begin{array}{l}\text { Weight } \\
(90)\end{array}$ & 0.385 & 0.317 & 0.98 & 0.028 & 0.14 & 1.773 & 0.178 & 0.31 \\
\hline
\end{tabular}

\subsection{Wire electrode:}

We use hard $0.25 \mathrm{~mm}$ brass wire in our research work. Brass Wirewas the successor to Copper wire and is still the most commonly used wire today. Brass, which is an alloy of Copper and Zinc, delivers a powerful combination of low cost, reasonable conductivity, high tensile strength, and improved flush ability.

\subsection{Experimental Procedure:}

Electronica ULTIMA 1F CNC WEDM machine is used in experiment. Here all the experiments are done using $0.25 \mathrm{~mm}$ brass wire. Pulse on time (Ton), Pulse off time (Toff), Peak current (IP), and servo voltage (SV) are the controllable parameters selected for this experiment and wire tension and fluid pressure is constant parameters. These Parameters are settled for rough cut, trim 1 cut and trim 2 cut according to doe table generated for each to facilitate final experiment.
Constant parameter's value for all cuts is shown in table 2.2. $0.25 \mathrm{~mm}$ Brass wire is used as wire material and P20 steel plate is used as workpiece material in this observation. Before experiment both surfaces of work piece were ground to a good surface finish with surface grinding machine for accurate measurement. $10 \times 10 \mathrm{~mm}$ square piece is cut with WEDM and Ra value and cutting rate is measured for each piece. Surface roughness tester TR110 is used to measure Ra value. Cutting rate is observed from display screen.

Taguchi's L9 orthogonal array was used to create the DOE table for the below mentioned factors and their levels using MINITAB 17 software. Practicals were performed using these parameters values.

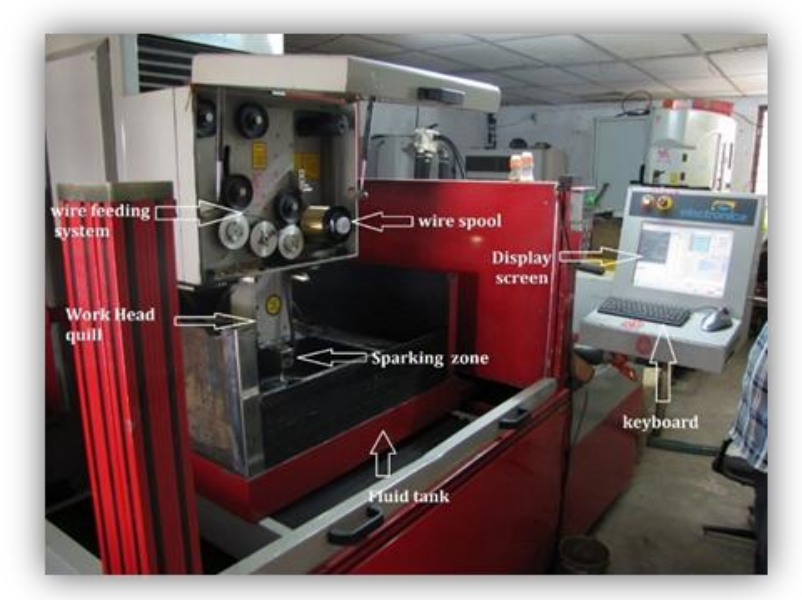

Fig 4: Experimental setup

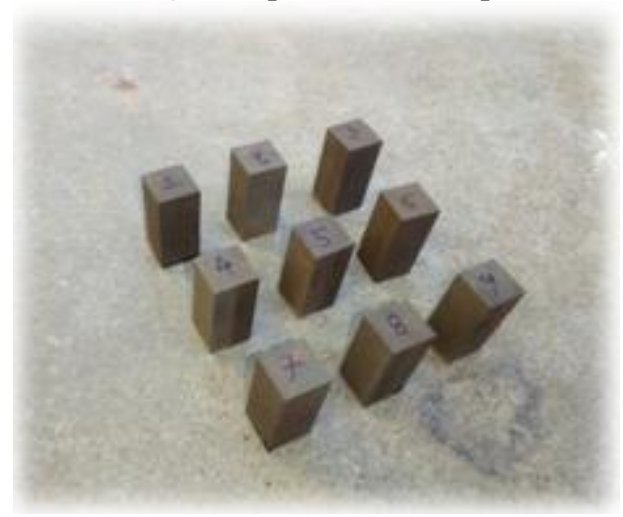

Fig 5:Machined Workpiece

Table 2.2: Constant parameters for experiments

\begin{tabular}{|l|l|l|l|}
\hline Factor & $\begin{array}{l}\text { Rough } \\
\text { cut }\end{array}$ & $\begin{array}{l}\text { Trim } \\
\mathbf{1}\end{array}$ & $\begin{array}{l}\text { Trim } \\
\mathbf{2}\end{array}$ \\
\hline $\begin{array}{l}\text { Wire } \\
\text { tension }\end{array}$ & 8 & 9 & 10 \\
\hline $\begin{array}{l}\text { Fluid } \\
\text { Pressure }\end{array}$ & 5 & 3 & 3 \\
\hline
\end{tabular}



ISSN : 2248-9622, Vol. 7, Issue 4, ( Part -5) April 2017, pp.72-76

Table 2.3: Selected Level of DOE for rough cut

\begin{tabular}{|l|l|l|l|}
\hline Factor & Level 1 & Level 2 & Level 3 \\
\hline Ton $(\mu \mathrm{s})$ & 310 & 315 & 320 \\
\hline Toff $(\mu \mathrm{s})$ & 54 & 58 & 62 \\
\hline IP $($ amp. $)$ & 11 & 12 & 13 \\
\hline Sv $(v)$ & 20 & 25 & 30 \\
\hline
\end{tabular}

Table 2.4: Selected Level of DOE for trim 1

\begin{tabular}{|l|l|l|l|}
\hline Factor & Level 1 & Level 2 & Level 3 \\
\hline To $(\mu \mathrm{s})$ & 210 & 220 & 230 \\
\hline Toff $(\mu \mathrm{s})$ & 52 & 55 & 58 \\
\hline IP $($ amp. $)$ & 10 & 11 & 12 \\
\hline Sv(V) & 15 & 20 & 25 \\
\hline
\end{tabular}

Table 2.5Selected Level of DOE for trim 2

\begin{tabular}{|l|l|l|l|}
\hline Factor & Level 1 & Level 2 & Level 3 \\
\hline $\operatorname{To}(\mu \mathrm{s})$ & 110 & 120 & 130 \\
\hline $\operatorname{Toff}(\mu \mathrm{s})$ & 50 & 53 & 56 \\
\hline $\mathrm{IP}(\mathrm{amp})$. & 110 & 114 & 118 \\
\hline $\mathrm{Sv}(\mathrm{V})$ & 15 & 25 & 35 \\
\hline
\end{tabular}

\section{RESULTS AND DISCUSSION}

The experimental results are collected for Surface roughness and cutting rate. Experiments were conducted using Taguchi (L9) experimental design methodology and there is one replicates for each experiment to obtain $\mathrm{S} / \mathrm{N}$ values. In the present study all the designs, plots and analysis have been carried out using Minitab statistical software. Smaller value of Roughness show the good surface quality of machined workpiece. Therefore, smaller is better is applied to calculate the $\mathrm{S} / \mathrm{N}$ ratio of SR.larger is better is applied to cutting rate.

Measurement of surface roughness: surface roughness of all four $10 \times 10 \mathrm{~mm}$ square pieces are measure using Surface roughness tester TR110.

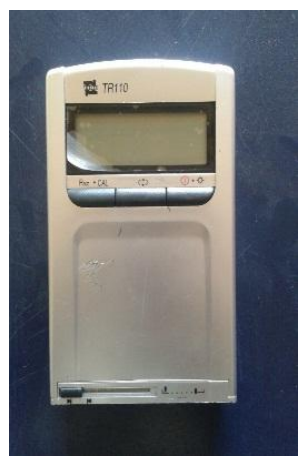

Fig6: surface roughness tester

Method:

Take workpiece and put it on surface roughness measurement table.TR110 has a probe tip which moves on the surface with three measuring distance L1 (0.25), L2 (0.80), and L3 (2.50). After measuring Ra value for L1, L2 and L3 length take the average value and find the final value for surface roughness.

\subsection{Analysis of SR (rough cut):}

The purpose of the analysis of surface roughness (SR) is to determine the factors and their interactions that have strong effects on the machining performance.

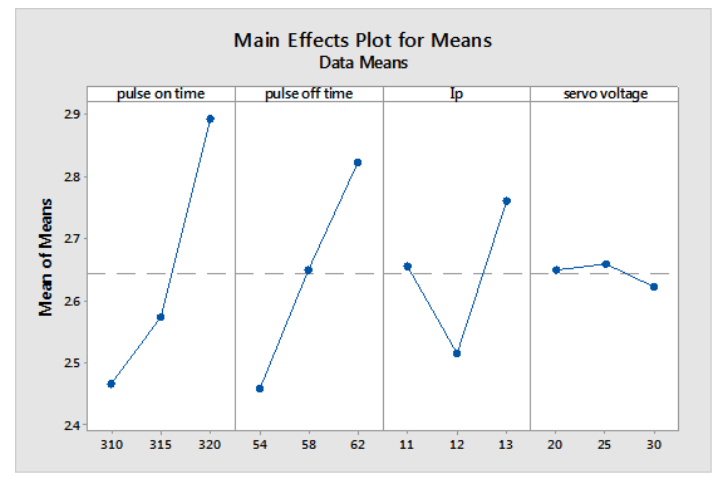

Fig7: Main effect plot for Means

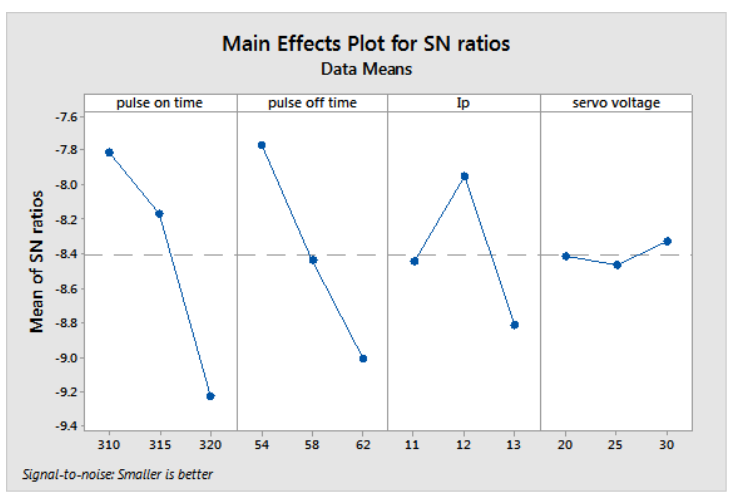

Fig 8: Main effect plot for $\mathrm{SN}$ ratio

Table 3.1: Response Table for Means

\begin{tabular}{|l|l|l|l|l|}
\hline LEVEL & Ton & Toff & Ip & SV \\
\hline 1 & 2.467 & 2.460 & 2.657 & 2.650 \\
\hline 2 & 2.573 & 2.650 & 2.517 & 2.660 \\
\hline 3 & 2.893 & 2.823 & 2.760 & 2.623 \\
\hline Delta & 0.427 & 0.363 & 0.243 & 0.037 \\
\hline Rank & 1 & 2 & 3 & 4 \\
\hline
\end{tabular}

Table 3.2: Response Table for Signal to Noise Ratios Smaller is better

\begin{tabular}{|l|l|l|l|l|}
\hline LEVEL & Ton & Toff & Ip & SV \\
\hline & & & - & - \\
1 & -7.816 & -7.769 & 8.444 & 8.419 \\
\hline & & & - & - \\
\hline & -8.171 & -8.434 & 7.953 & 8.469 \\
\hline 3 & -9.227 & -9.011 & - & - \\
\hline Delta & 1.411 & 1.242 & 0.863 & 8.326 \\
\hline Rank & 1 & 2 & 3 & 4 \\
\hline
\end{tabular}


The optimal machining performance for Surface roughness was obtained as $310 \mu$ s pulse-on time, $54 \mu$ s pulse-off time, 12 Amp. IP and 30v gap voltage settings that give the batter Ra value. Fig 6 and 7 shows the effect of machining parameters on the SR.

\subsection{Analysis of cutting rate (rough cut):}

The purpose of the analysis of cutting rate is to determine the factors and their interactions that have strong effects on the machining performance.

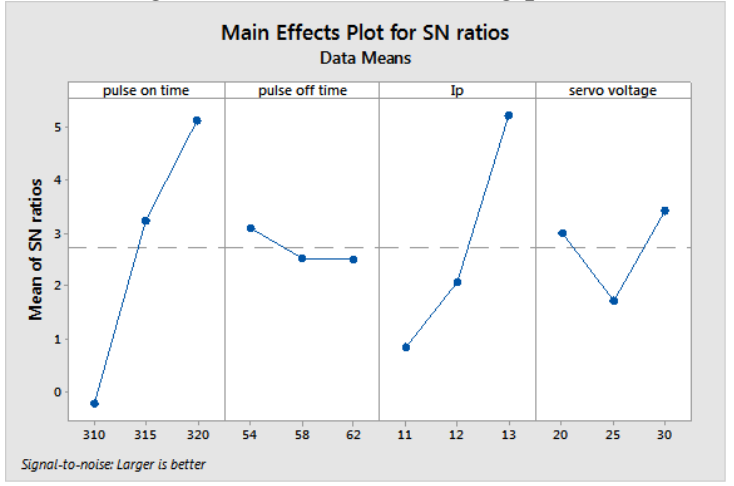

Fig 9: Main effect plot for Means

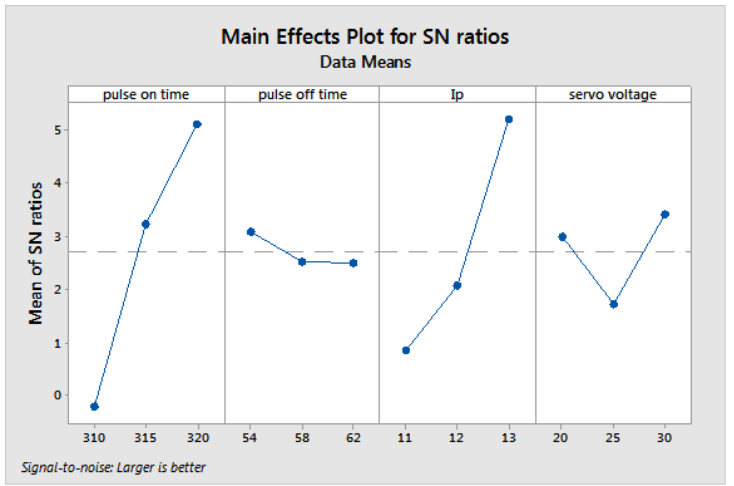

Fig 10: Main effect plot for $\mathrm{SN}$ ration

Table 3.3: Response Table for Mean

\begin{tabular}{|l|l|l|l|l|}
\hline LEVEL & Ton & Toff & Ip & SV \\
\hline 1 & 2.467 & 2.460 & 2.657 & 2.650 \\
\hline 2 & 2.573 & 2.650 & 2.517 & 2.660 \\
\hline 3 & 2.893 & 2.823 & 2.760 & 2.623 \\
\hline Delta & 0.427 & 0.363 & 0.243 & 0.037 \\
\hline Rank & 1 & 2 & 3 & 4 \\
\hline
\end{tabular}

Table 3.4: Response Table for Signal to Noise Ratios Smaller is better

\begin{tabular}{|l|l|l|l|l|}
\hline LEVEL & Ton & Toff & Ip & SV \\
\hline 1 & -7.816 & -7.769 & -8.444 & -8.419 \\
\hline 2 & -8.171 & -8.434 & -7.953 & -8.469 \\
\hline 3 & -9.227 & -9.011 & -8.816 & -8.326 \\
\hline Delta & 1.411 & 1.242 & 0.863 & 0.143 \\
\hline Rank & 1 & 2 & 3 & 4 \\
\hline
\end{tabular}

The optimal machining performance for cutting rate was obtained at $320 \mu$ s pulse-on time, $54 \mu \mathrm{s}$ pulse-off time, $30 \mathrm{v}$ gap voltage and IP 13A settings that give the maximum cutting rate. Fig 8 and 9 shows the effect of machining parameters on the cutting rate. That cutting rate increases with the increase of pulse on time and decreases with increase in pulse off time, cutting rate is increased with increase in IP and then decreases but gap voltage has mixed effect on cutting rate.

\subsection{Effect of trim cutting}

From our practical observation we have generated table 3.5 which shows the value of surface roughness for different cuts. Result data shows that roughness value significantly getting better and better during trim cutting operation.

Table 3.5: Ra value for different cuts

\begin{tabular}{|l|l|l|l|}
\hline \multirow{2}{*}{$\begin{array}{l}\text { Sr } \\
\text { no. }\end{array}$} & \multicolumn{4}{|l|}{ Surface roughness $(\mu \mathrm{m})$} \\
\cline { 2 - 4 } & Rough cut & Trim 1 & Trim 2 \\
\hline 1 & 2.30 & 2.08 & 1.18 \\
\hline 2 & 2.36 & 1.58 & 1.28 \\
\hline 3 & 2.74 & 1.63 & 1.70 \\
\hline 4 & 2.24 & 2.28 & 1.90 \\
\hline 5 & 2.70 & 2.68 & 1.60 \\
\hline 6 & 2.78 & 2.54 & 1.62 \\
\hline 7 & 2.84 & 2.43 & 1.75 \\
\hline 8 & 2.89 & 2.67 & 1.82 \\
\hline 9 & 2.95 & 2.50 & 1.86 \\
\hline
\end{tabular}

Fig 10 shows the details of $10 \times 10 \mathrm{~mm}$ square piece which is machined with multipass cutting operation in Wire EDM.

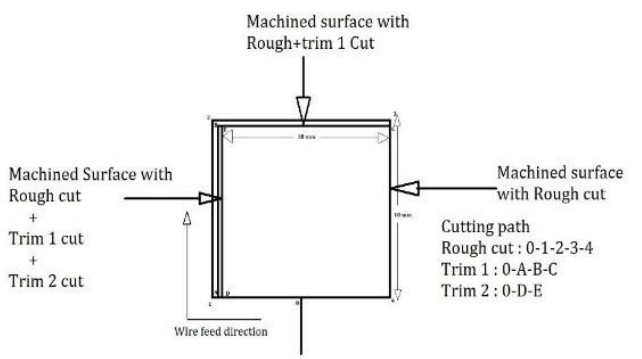

Fig 11: details of machined piece

III.

\section{CONCLUSION}

After performing experiment with multipass cutting strategy using $0.25 \mathrm{~mm}$ hard brass wire we conclude that the surface finish improves significantly in trim cutting operation. Experimental results show that the increasing the pulse on time and peak current increasing the cutting rate, surface roughness. This is because the discharge energy increases with pulse on time and the number of discharges within a given period becomes more. From the experiment results pulse 
on time is the greatest effect on cutting rate and surface roughness compare to other parameters. At higher pulse off time, less number of discharges in a given time during machining, and results in lessercutting rate. Due to less no. of discharge, small craters on the surface. Hence, surface roughness is getting minimum. Increasing servo voltage decreases the discharge energy across the electrodes which results in reduce cutting rate.

\section{REFERENCES}

[1] Zhe Chena, Johan Moverarea, Ru Lin Penga, Sten Johanssona. Surface Integrity and Fatigue Performance of Inconel 718. Procedia CIRP 45 (2016) 307 - 310.

[2] Yadong Gong Yao Sun Xuelong Wen Chao Wang1 Qi Gao1. Experimental study on surface integrity of Ti-6Al-4V machined by LS-WEDM. Int $\mathrm{J} \mathrm{Adv}$ Manuf Technol.

[3] G.Ugrasen, H.V.Ravindra, G.V.Naveen Prakash, Y.N.Theertha Prasad. Optimization of process parameters in wire EDM of HCHCr. Materials Today: Proceedings 2 (2015) 2443 - 2452.

[4] PrashantSinha, Rajeev Kumar, G.K.Singh, DainThomas, TusharSrivastava. Optimization of Wire EDM of AISI D3 Tool Steel using Orthogonal. Materials Today: Proceedings 2 (2015) 2512 - 2521.

[5] Sameh Habib1 \& Akira Okada2. Experimental investigation on wire vibration during fine wire. Int $\mathbf{J} \mathrm{Adv}$ Manuf Technol.

[6] Chuanliang Cao, Xianglin Zhang, Xiang Zha, Chunfa Dong. Surface integrity of tool steels multi-cut by wire electrical. Procedia Engineering 81 (2014) 1945 1951.

[7] M. MANJAIAH1, S. NARENDRANATH1, $S$. BASAVARAJAPPA2, V. N. GAITONDE3. Wire electric discharge machining characteristics of. Trans.
Nonferrous Met. Soc. China 24(2014) 3201-3209.

[8] Farnaz Nourbakhsha, K. P. Rajurkarb, A. P. Malshec, Jian Caod. Wire electrodischarge machining of titanium alloy

[9] M. Durairaja, D. Sudharsunb, N. Swamynathanb. Analysis of Process Parameters in Wire EDM with Stainless Steel using Single Objective Taguchi Method and Multi Objective GreyRelational Grade. Procedia Engineering 64 (2013) 868 - 877.

[10] S.L. Soo, M.T. Antara, D.K. Aspinwalla, C. Sagec, M. Cuttelld, R. Pereze, A.J. Winnf. The effect of wire electrical discharge machining on the fatigue life. Procedia CIRP 6 (2013) 216 - 220.

[11] Ali Vazini Shayana, Reza Azar Afzac, Reza Teimourib. Parametric study along with selection of optimal solutions in dry wirecut machining of cemented tungsten carbide (WC-Co). Journal of Manufacturing Processes (2013).

[12] K.Lingadurai, B.Nagasivamuni, M.Muthu Kamatchi. Selection of Wire Electrical Discharge Machining Process. J. Inst. Eng. India Ser. C (April-June 2012) 93(2):163-170.

[13] Aniza Aliasa, Bulan Abdullaha, Norliana Mohd Abbasa. INFLUENCE OF MACHINE FEED RATE IN WEDM OF TITANIUM. Procedia Engineering 41 (2012) 1806 - 1811.

[14] J.A. Sanchez, J.L. Rodil, A. Herrero ,L.N. Lopez de Lacalle, A. Lamikiz. On the influence of cutting speed limitation on the accuracy of wire-EDM corner-cutting. Journal of Materials Processing Technology 182 (2007) 574-579.

[15] J.-P. Kruth (1), B. Lauwers (2), B. Schacht,J. Van Humbeeck.CompositeWires with High Tensile Core for Wire EDM. 